\title{
EVAPORITOS COMO RECURSOS MINERAIS
}

\author{
Maria A. M. da Silva ${ }^{1}$, B. Charlotte Schreiber ${ }^{2}$ \& Carla L. dos Santos ${ }^{1}$
}

Received August 24, 2000 / Accepted August 02, 2001

Evaporitos são rochas sedimentares comumente formadas em ambientes de sedimentação de baixo aporte de terrígenos, submetidos a clima seco onde as taxas de evaporação das águas são elevadas permitindo a formação de uma salmoura a partir da qual minerais evaporíticos se formam. O potencial econômico dessas rochas é enorme, valendo salientar que o cloreto de sódio ou sal de cozinha é um dos minerais evaporíticos de maior importância para o ser humano. Além disso, os evaporitos costumam estar associados a ambientes altamente produtivos em matéria orgânica e no registro geológico é conhecida a associação de campos gigantes de petróleo e seqüências espessas de evaporitos. Neste texto, iremos abordar os mecanismos mais importantes de formação dos evaporitos e seus ambientes deposicionais, apresentando os depósitos mais importantes onde evaporitos são economicamente explorados, e a importante relação com o petróleo. Ao final, serão discutidos os aspectos mais importantes dos evaporitos Aptianos, formados durante a fase golfo da evolução do Oceano Atlântico Sul, e que apresentam na sua porção relativa à bacia de Sergipe, importantes jazidas de silvinita, carnalita e taquidrita.

Palavras-chave: Rochas sedimentares; Evaporitos; Bacia de Sergipe; Recursos minerais; Oceano Atlântico Sul.

EVAPORITES AS MINERAL RESOURCES-Evaporites are sedimentary rocks commonly formed in sedimentary environments of low terrigenous input, under arid climate where the evaporation rates are high enough for the formation of brines from which the evaporitic sediments are generated. The economic potential of these rocks is enormous, and halite, the commonly consumed salt, is one of the most important evaporitic minerals for the human beings. In addition to that, evaporitic deposits are frequently associated to environments rich in the production of organic matter, and in the geologic record the association of evaporites and giant petroleum fields is widespread. In this article, we will discuss the processes of evaporite formation and its depositional environments, the most important deposits in the world where evaporites are economically explored will be presented, and the strong association of evaporites and petroleum. The Aptian evaporites of the Sergipe Basin, formed during the initial phase of opening of the South Atlantic Ocean, will be given as an example of exploration of sylvinite, carnallite and tachydrite.

Key words: Sedimentary rocks; Evaporites; Sergipe basin; Mineral resources; South Atlantic Ocean.

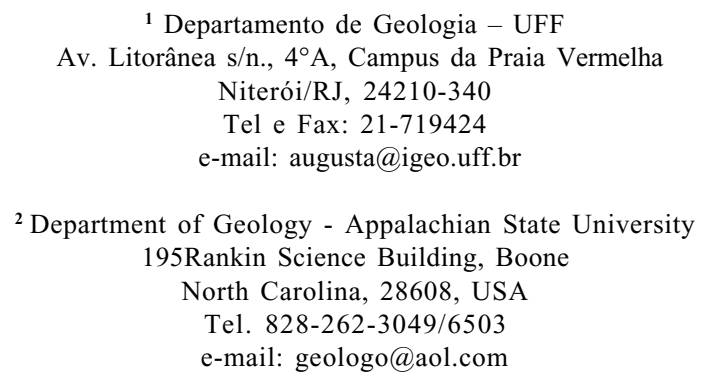




\section{INTRODUÇÃO}

Os estudos sobre rochas evaporíticas começaram há mais de 120 anos, porém com uma abordagem basicamente química. Gradativamente os estudos se tornaram mais sedimentológicos até culminar na década de sessenta do século 20 quando houve grande mudança na abordagem e os estudos passaram a ter uma visão mais atualística: os ambientes modernos vem sendo utilizados como modelos para o entendimento de paleoambientes deposicionais. A razão principal dessa mudança foi a descoberta de faciologias evaporíticas costeiras na Costa Trucial do Golfo da Pérsia (Curtis et al., 1963), em ambientes de planícies de supramaré denominados pelos árabes de "sabkhas". Estes estudos forneceram modelos de fácies e seqüências deposicionais que passaram a ser utilizados na geologia do petróleo. Assim que, os estudos modernos levam em consideração os vários aspectos geológicos e sedimentológicos dos depósitos evaporíticos e não somente a sua composição ou natureza química.

Depósitos evaporíticos são encontrados hoje em muitas regiões do mundo, sempre em ambientes onde a razão de evaporação excede a razão de precipitação ou outra chegada de água; outro importante fator controlador é a discreta contribuição sedimentar de terrígenos de fora da bacia. Tais ambientes podem ser tanto de características continentais como marinhas, desde desertos até mares hipersalinos. Geralmente, ocorrem nas latitudes de $30^{\circ} \mathrm{N}$ e S onde os ventos frios descendem, porém podem ocorrer em áreas tão diversas como na Antártica ou em regiões equatoriais onde o clima é controlado por cinturões orográficos.

O conhecimento atual sobre os evaporitos deixa claro que a sua importância sob o ponto de vista econômico não se restringe aos próprios minerais evaporíticos (exemplo: trona, gipsita, anidrita, halita, silvinita, etc.), ou sua importante função como selante do reservatório de petróleo, mas também como hospedeiro de vários minérios. A freqüente associação com petróleo, onde cerca de $70 \%$ dos campos de petróleo gigantes em rochas carbonáticas estão relacionados a depósitos evaporíticos (Zhang Yi Yang, 1981, in: Warren, 1989), permite reconhecer a importância de se estudar e entender a geologia e sedimentologia dessas rochas sedimentares.

\section{MODOS DE FORMAÇÃO}

Como mencionado, os ambientes de formação dos evaporitos ocorrem tanto em situações de caráter continental como marinho. $\mathrm{O}$ ambiente marginal marinho é representado pelas planícies do tipo sabkha e salinas, porém os evaporitos podem ser formados em ambientes marinhos rasos e profundos; além desses, os lagos salinos em áreas continentais são extremamente importantes para a formação de camadas espessas de sais em seqüências lacustres.

A química da água do mar moderna é dominada pelos íons $\mathrm{Na}+$ e $\mathrm{Cl}$-, e quantidades menores de $\mathrm{SO}_{4}{ }^{2}, \mathrm{Mg}^{+}, \mathrm{Ca}^{+}{ }^{2}, \mathrm{~K}+{ }^{1}, \mathrm{CO}^{-2}{ }^{2} \mathrm{e}$ HCO3-1. Quando a água do mar é evaporada, uma suíte de minerais é precipitada em ordem previsível. O primeiro mineral é um carbonato, comumente aragonita ou calcita, quando a solução alcança a concentração equivalente a duas vezes à da água do mar. A seguir ocorre a precipitação de sulfato, geralmente na forma de gipsita ou anidrita, quando a salmoura se encontra em uma concentração equivalente a cinco vezes àquela da água do mar. Em concentrações de onze a doze vezes, a halita precipita. Após essa precipitação, sais complexos de potássio e magnésio (exemplo, silvinita), entre outros, podem precipitar em concentrações superiores a sessenta vezes à original. Os tipos de sais complexos e as respectivas salinidades da salmoura variam de acordo com a temperatura ou com os níveis de matéria orgânica presentes na salmoura.

Três fatores críticos controlam a formação dos minerais evaporíticos e seu acúmulo: a baixa umidade relativa do ar, a temperatura, o conteúdo iônico inicial e suas relações. Isto ocorre independente do caráter continental ou marinho da ambiente de formação. Neste trabalho iremos abordar somente os ambientes marinhos, começando pelos marginais ou costeiros.

\section{Sabkhas:}

Ambientes costeiros onde ocorrem evaporitos são áreas essencialmente de baixo aporte de sedimentos clásticos e altas taxas de evaporação. Nestes ambientes encontra-se uma planície de sal denominada pelos árabes de sabkha (Fig. 1). 


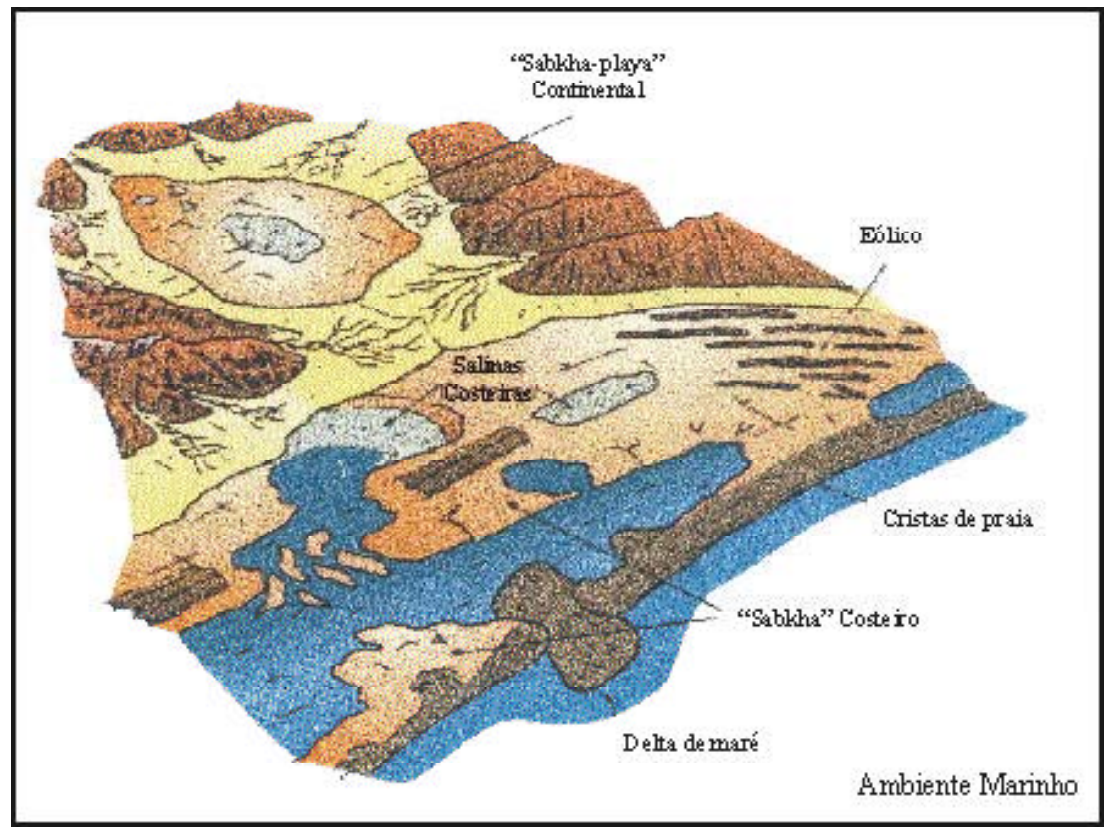

Figura 1 - Esquema ilustrativo dos principais ambientes evaporíticos modernos (os ambientes de águas profundas e de plataforma não são encontrados atualmente). Modificado de Kendall, 1984.

Pesquisas sobre esses tipos de ambientes costeiros são relativamente recentes e datam da década de 60 , quando da descoberta de anidrita em sabkhas da Costa Trucial do Golfo da Pérsia (Curtis et al., 1963). Desde então, a Costa Trucial, a Península de Qatar e a Baja Califórnia tornaram-se áreas clássicas para o estudo da formação de evaporitos em sabkhas.

Os evaporitos formados em sabkhas, adjacentes a um corpo d'água (marinho ou não marinho) em clima árido, são na sua grande maioria componentes de um perfil de solo nas zonas vadosas e freáticas. O sedimento evaporítico se forma dentro de um sedimento hospedeiro, mais abundante, e que se comporta como matriz, e cuja composição pode ser tanto carbonática, siliciclástica ou mista. Gipsita, anidrita e halita são os minerais evaporíticos mais comuns, ainda que o influxo de águas continentais possa causar o aparecimento de inúmeros minerais dependendo da química de tais águas.

As acumulações sedimentares em sabkhas geram comumente seqüências pouco espessas, variando de $30 \mathrm{~cm}$ até 1 ou $2 \mathrm{~m}$ (Schreiber e Tabakh, 2000), com cada ciclo truncado por superfícies que são na verdade superfícies de deflação geradas pelo vento ou água (neste caso, durante as tempestades). No registro geológico, encontram-se freqüentemente seqüências repetidas e sobrepostas de depósitos de sabkha.
A associação de fácies sedimentares tais como esteiras algálicas formadas na região intermaré (Fig. 2 A e B), nódulos e estruturas enterolíticas de sulfato de cálcio, tanto gipsita como anidrita, característico da porção supramaré (Fig. 4 A), e cubos bem como formas esqueletais de halita em uma matriz carbonática ou siliciclástica, costumam ser boas evidências para a identificação de um ambiente marginal do tipo sabkha.

\section{Águas Rasas:}

Os depósitos evaporíticos modernos de águas rasas estão se formando em lagos continentais, lagoas e salinas. O exemplo mais bem documentado vem das salinas do Sul Australiano aonde as seqüências de gipsita subaquosas chegam a 10 metros de espessura tendo sido formados ao longo dos últimos 6000 anos (Warren, 1989). Outros trabalhos têm sido realizados com os evaporitos laminados de natureza subaquosa da Baja Califórnia (SO dos Estados Unidos), Sicília (Itália) e Oriente Médio. O estudo da formação dos sais em salinas (naturais e artificiais), no entanto tem sido de grande importância para o entendimento da formação de evaporitos em ambientes de águas rasas (lâminas d'água inferiores a $50 \mathrm{~m}$, segundo Schreiber, 1986), principalmente no que diz respeito aos processos e exemplos de formação de fácies sedimentares evaporíticas.

Muito do que se sabe a respeito dos evaporitos 

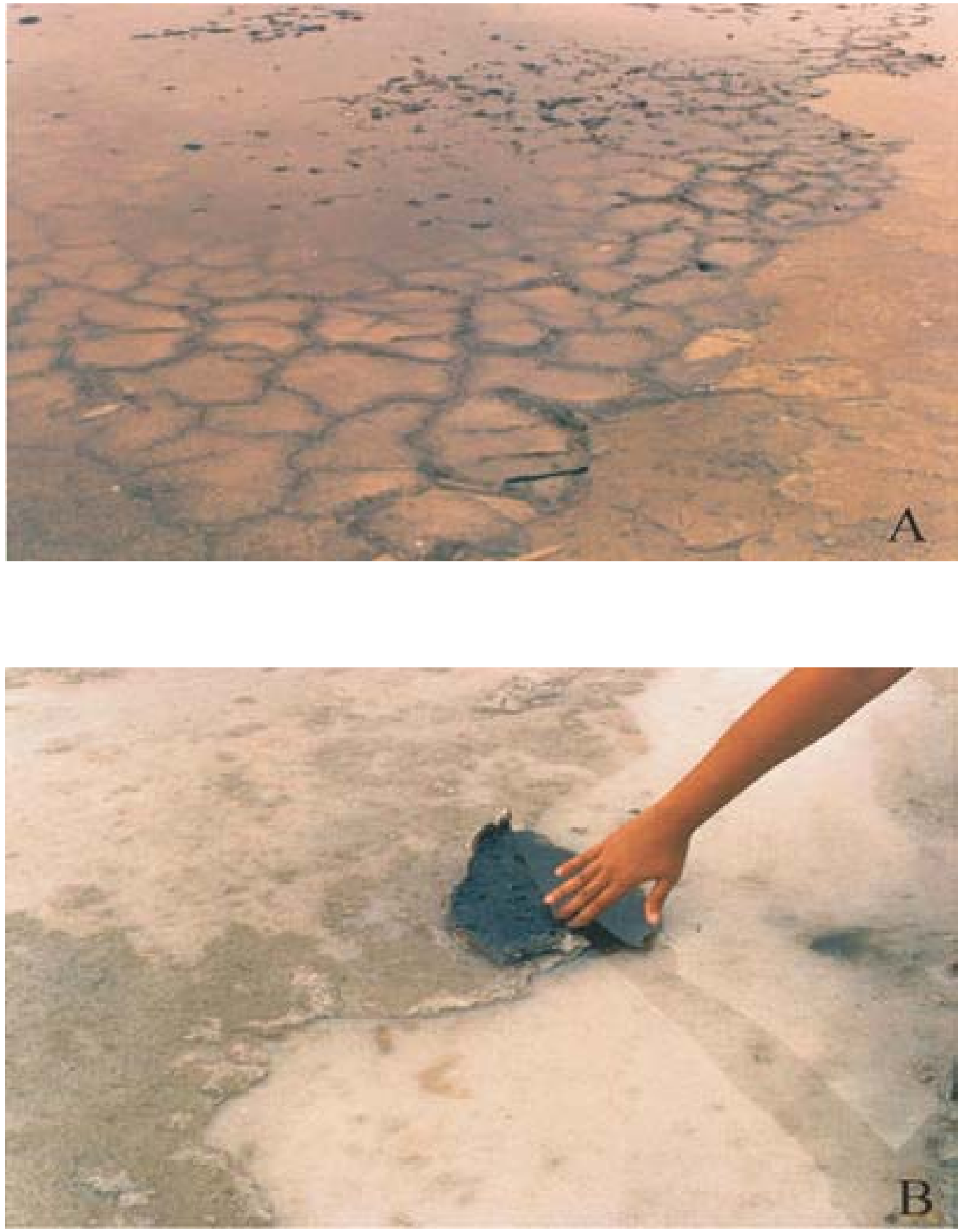

Figura 2 - (A) Esteiras algálicas em processo de ressecamento e formação de gretas. Caneta na parte inferior da foto como escala. (B) Greta de ressecamento mostrando, na base, acúmulo de matéria orgânica em ambiente carbonático evaporítico. Salinas da Lagoa de Araruama, R.J. 


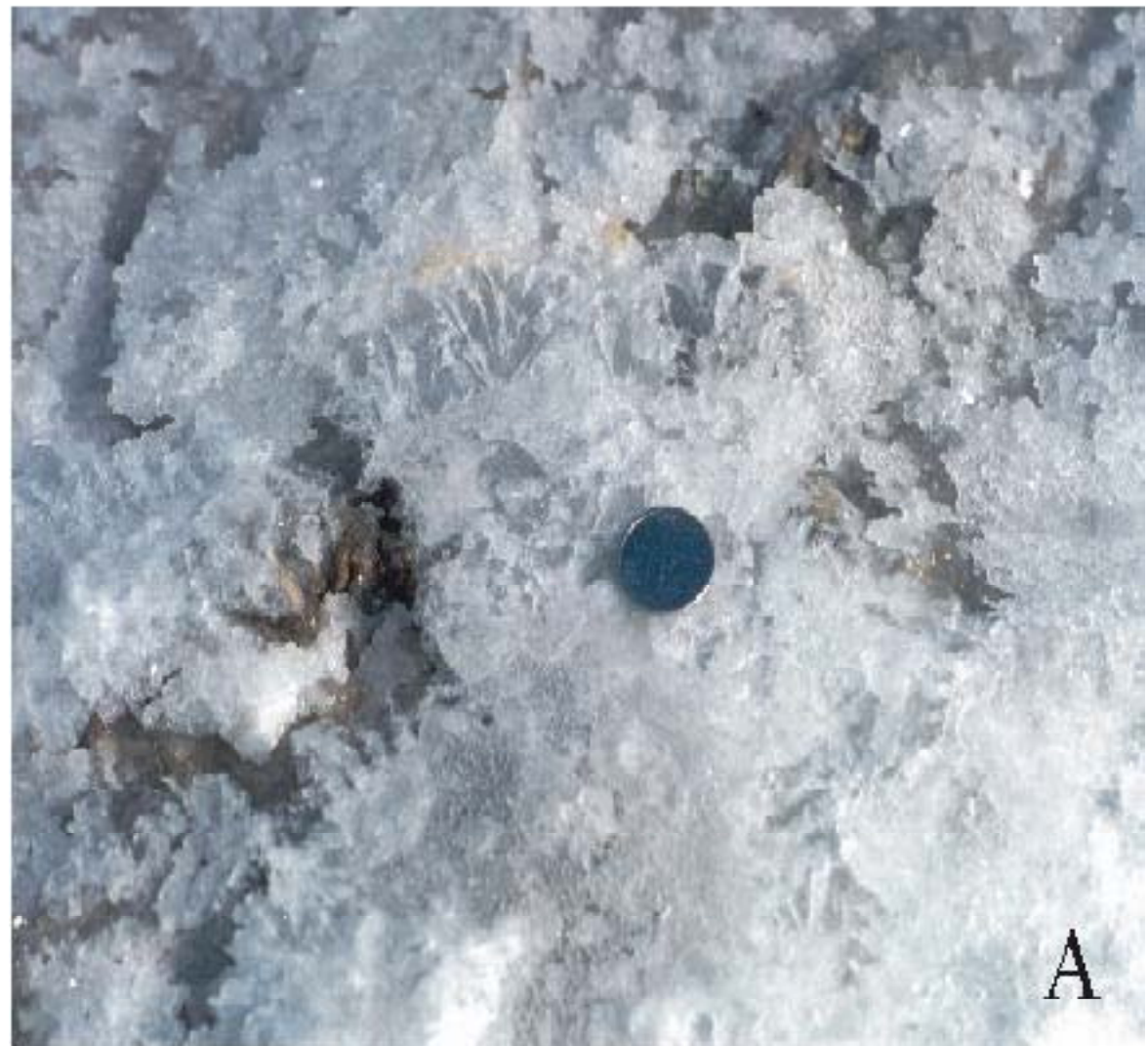

Figura 3 - (A) Halita chevron, Salinas da Lagoa de Araruama, RJ. Tampa da máquina no centro da foto como escala;

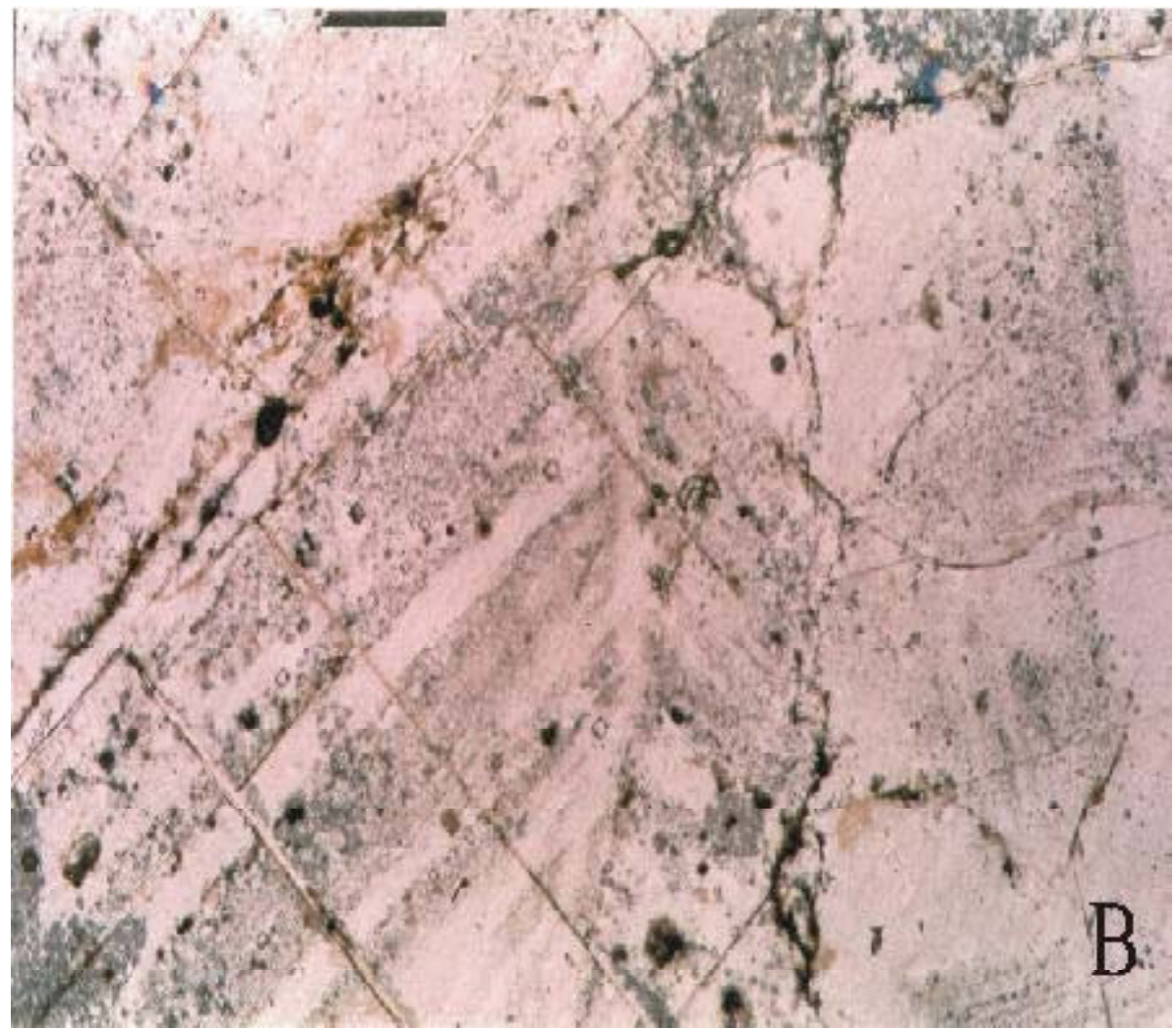

Figura 3 - (B) Halita chevron, Evaporitos Aptianos da Bacia de Sergipe. Barra no alto da foto corresponde a aproximadamente $0,5 \mathrm{~mm}$ 


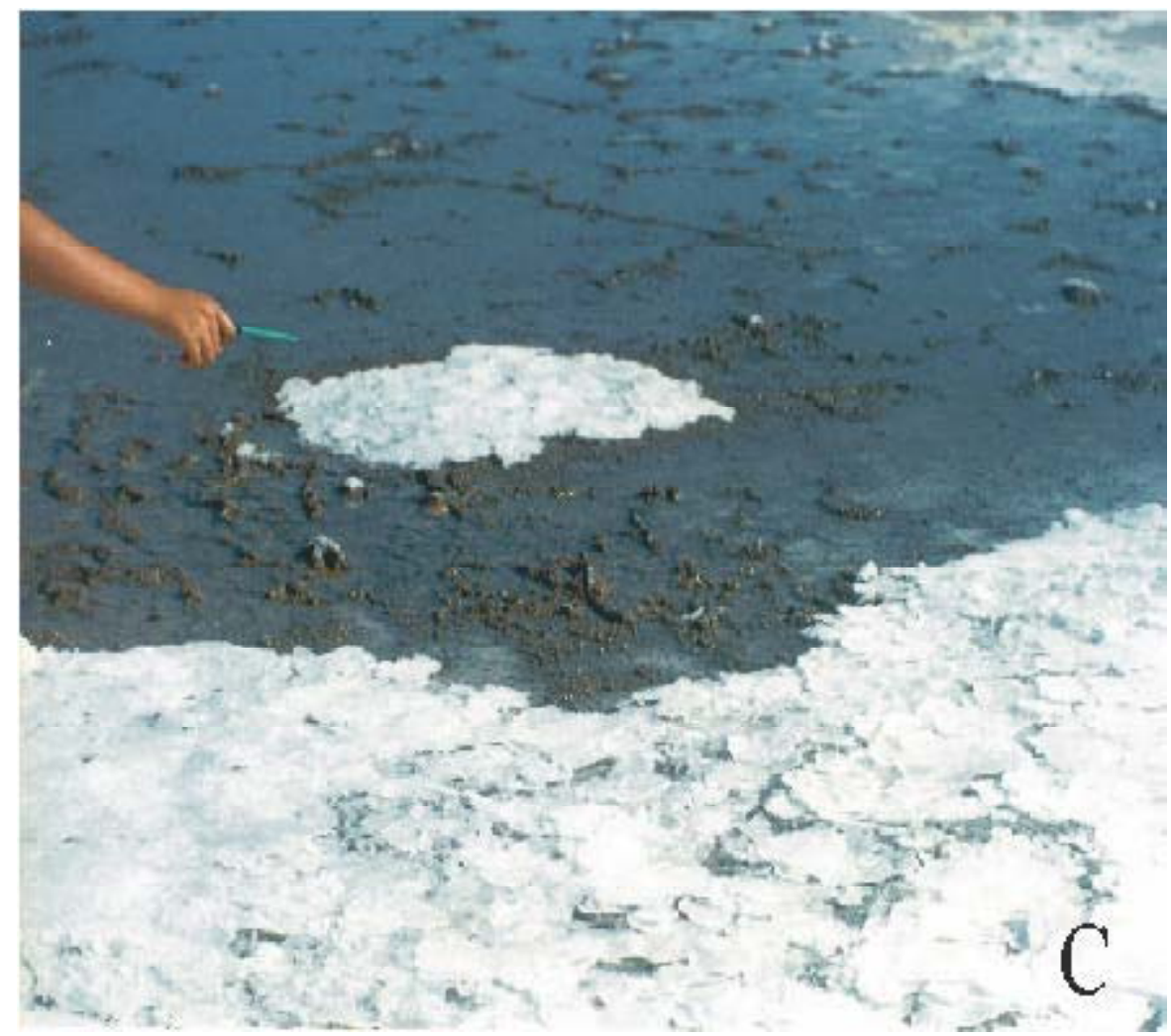

Figura 3 - (C) Acúmulo de cristais de halita com matéria orgânica, Salinas da Lagoa de Araruama, RJ.

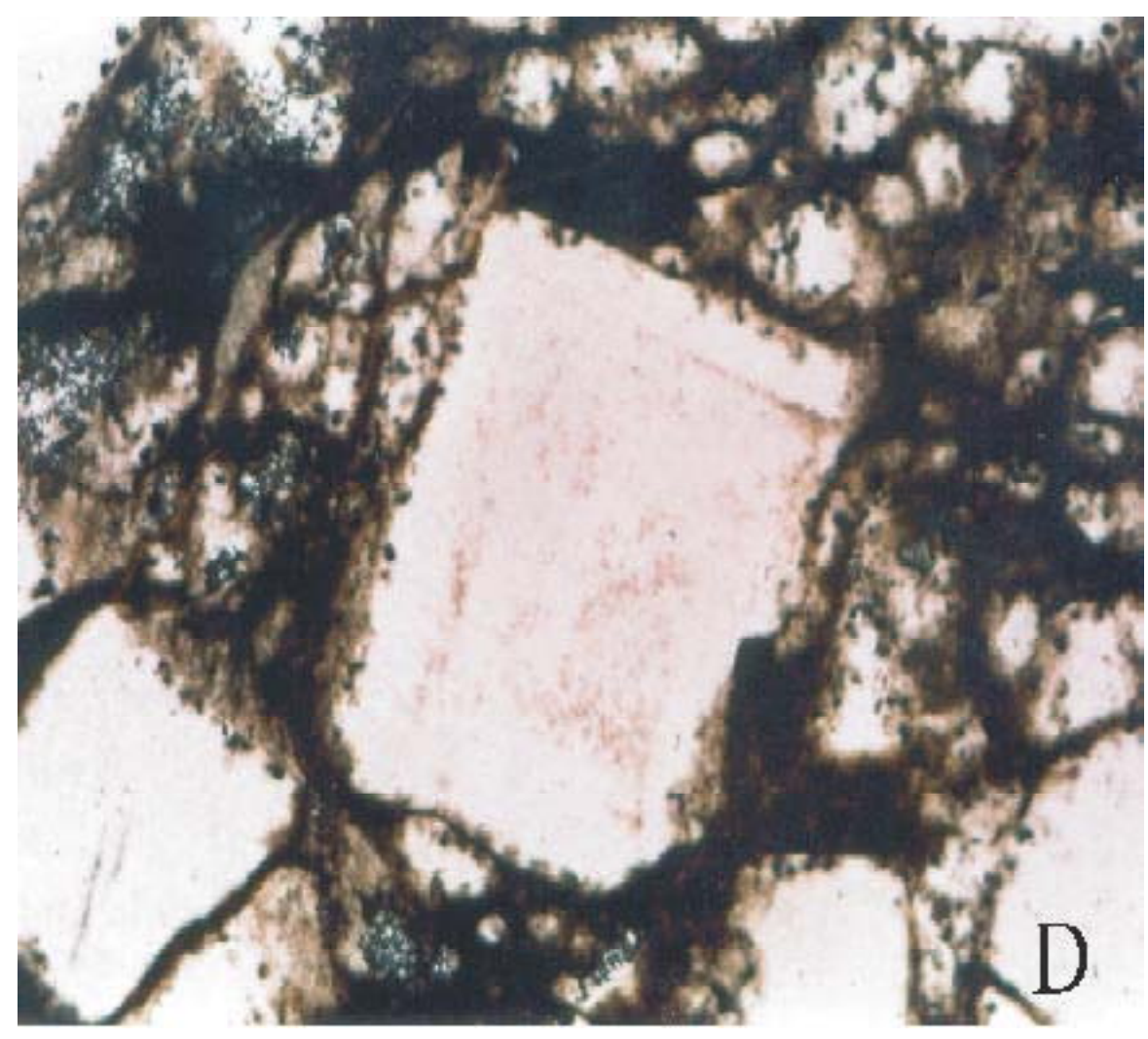

Figura 3 - (D) Cubos de halita envoltos com matéria orgânica, Membro Ibura da Formação Muribeca, Aptiano da Bacia de Sergipe. Face do cubo tem cerca de $0,5 \mathrm{~mm}$. 
de águas rasas e fácies sedimentares associadas vem da observação em salinas artificiais. Os primeiros tanques que recebem água do mar, ou água de lagunas e enseadas pré-concentradas, vão apresentar os primeiros minerais de carbonatos cuja precipitação é fortemente controlada pelas algas e bactérias presentes na água. Geralmente, esteiras algálicas e outras formas de crescimento algálico se desenvolvem; as esteiras apresentam uma textura de borracha e caso ressequem formam verdadeiras gretas que se assemelham a pedaços de borracha (Fig. 2 B). Grande quantidade de matéria orgânica em estado reduzido pode ser encontrada no fundo desses tanques (Fig. 2 B).

Os próximos tanques recebem águas com altas salinidades $(150-320 \mathrm{~g} / \mathrm{L})$ e neste ambiente os sulfatos, gipsita ou anidrita, se precipitam. No entanto é nos cristalizadores de sal quando a salmoura já se encontra com salinidades superiores a 10 vezes a da água do mar que a halita, ou sal de cozinha $(\mathrm{NaCl})$ precipita. Ocorre nucleação desse sal tanto na superfície da salmoura, gerando cristais que podem acabar depositados no fundo, como também pode ocorrer crescimento de cristais no fundo da bacia na forma de crostas e cristais do tipo "chevron" (Figs. 3 $\mathrm{A}$ e B). Essas várias morfologias apresentam potencial de preservação e podem ser utilizadas nas seqüências evaporíticas antigas como diagnósticas do ambiente de formação.

Neste ambiente de água rasa é importante realçar o conteúdo de matéria orgânica presente (Figs. $3 \mathrm{C}$ e D): ocorre variação da fauna e flora com o aumento progressivo da salinidade, o que acarreta a diminuição da diversidade das espécies, porém ocorrendo uma explosão das espécies resistentes às salinidades altas. Evans \& Kirkland (1988) documentaram a alta produtividade desses ambientes e inúmeros autores estudaram os biomarcadores típicos desse universo orgânico (Benalioulhaj et al., 1994 in: Schreiber et al. 2001).

\section{Águas profundas:}

Este ambiente evaporítico é o menos compreendido, e não existe hoje nenhum ambiente marinho profundo para servir de exemplo. O exemplo mais próximo é o Mar Morto, onde se encontra um pacote de sedimentos evaporíticos de natureza continental formado em um ambiente subaquoso de cerca de 300 metros de lâmina d'água, no caso uma salmoura (Warren, 1989). A profundidade da água dessas bacias, de modo geral, é de difícil estimação, e evidências geoquímicas vêm sendo utilizadas para auxiliar nessa avaliação. O conteúdo de $\mathrm{Sr}$ na Formação Lisan (Pleistoceno do Mar Morto), permite a estimativa de profundidades de 400 - 600 metros para a deposição evaporítica Pleistocênica nessa bacia, superior aos atuais 300 metros (Katz et al., 1977 in: Warren, 1989)). De qualquer modo, a profundidade da água deve ser abaixo do nível de base da onda e suficientemente profunda e com um volume suficiente para atuar como um "buffer" químico. Para que uma espessura substancial de sais possa se acumular em águas profundas, a água de fundo deve estar saturada com gipsita e halita.

Pacotes extensos e espessos de evaporitos laminados (até mesmo ritmitos) onde os pares de lâminas são representados principalmente por carbonato - sulfato, halita - sulfato e halita - matéria orgânica (Fig. 4 B) implica profundidades de água elevadas, com certeza abaixo do nível de onda (exemplo, a Série Zechstein, Permiano do NO da Europa). A forte associação lateral desses depósitos com fluxos de massa a turbiditos de natureza evaporítica, implica também águas mais profundas do que as de plataforma continental de modo geral (Warren, 1989).

\section{RECURSOS MINERAIS EVAPORÍTICOS}

Os principais mais importantes, depósitos econômicos de evaporitos são encontrados nas bacias (Fig. 5): (1) Delaware , Permiano do Texas e New México nos Estados Unidos; (2) Zechstein, Permiano do NO da Europa; (3) Louann, Jurássico do Golfo da México; (4) Hormuz, Pré-Cambriano, Golfo da Arábia; (5) Bacias Miocênicas (Messiniano) em torno do Mar Mediterrâneo; (6) Michigan, SilurianoDevoniano, Norte dos Estados Unidos; (7) Elk Point, Devoniano, Canadá ; (8) Moscou, Devoniano, Rússia; (9) Grupo McArthur, Proterozoico, Austrália; (10) Bacia de Sergipe, Cretáceo (Aptiano), Margem Continental Leste do Brasil, além de outros.

Os minerais mais comuns e economicamente mais utilizados são gipsita/anidrita (Fig. 6), halita, tanto 

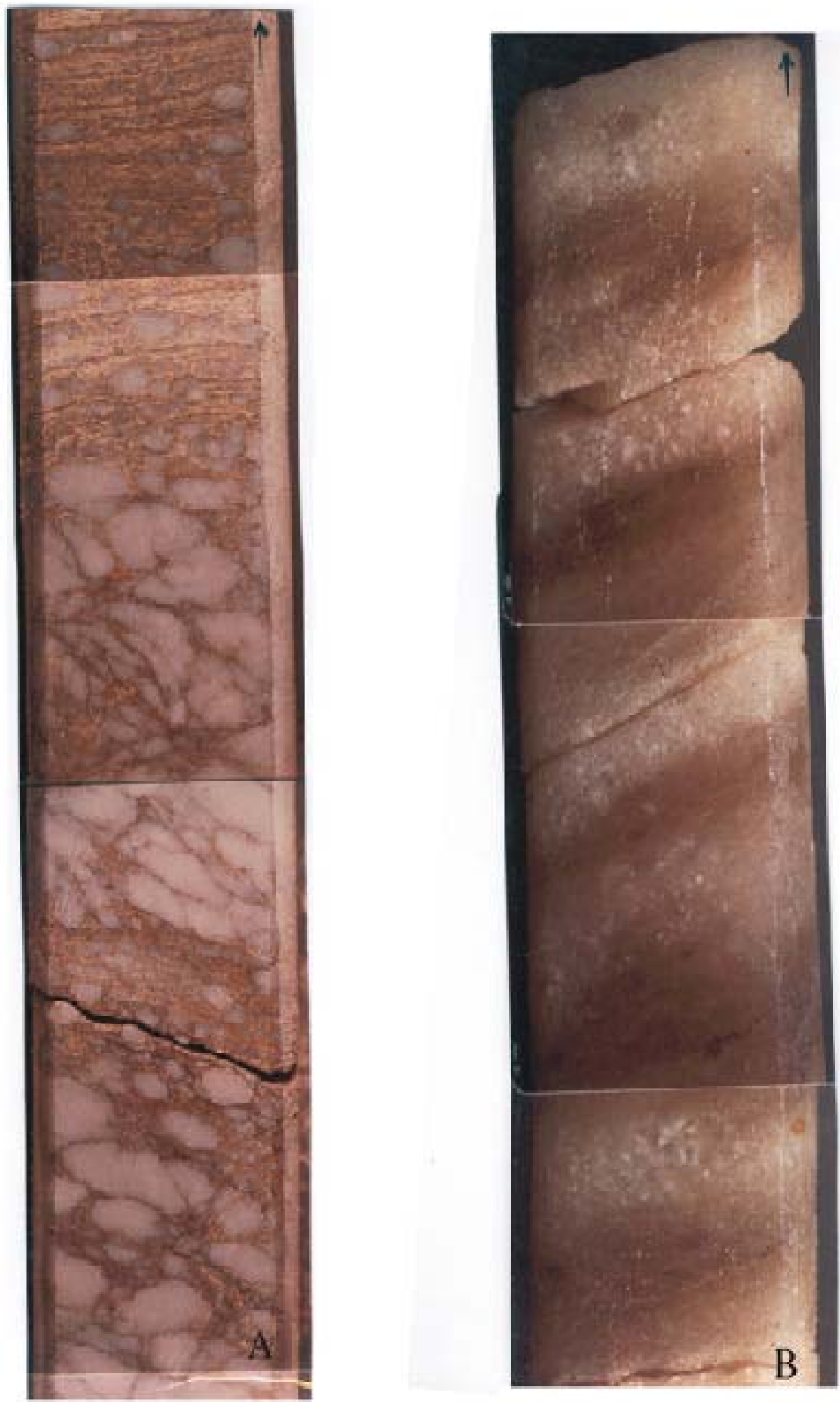

Figura 4 - (A) Nódulos de anidrita. (B) Halita bandeada com matéria orgânica, exemplos do Membro Ibura da Formação Muribeca, Aptiano da Bacia de Sergipe. A seta corresponde a cerca de $1 \mathrm{~cm}$ aproximadamente. 


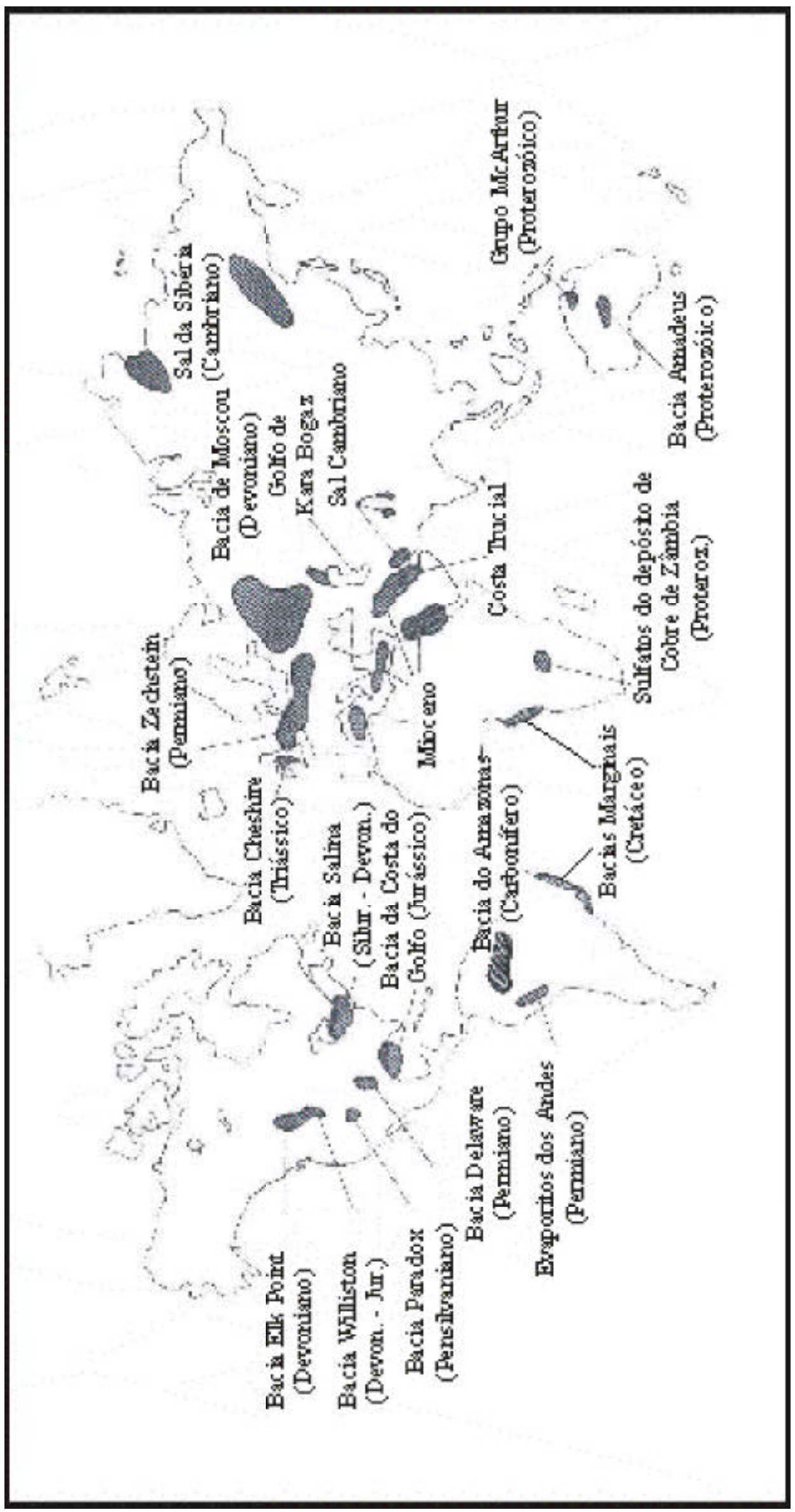

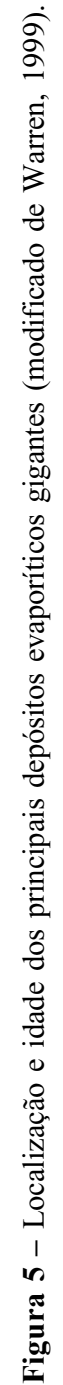


moderna, extraída das salinas (Fig. 7), como antigas, extraídas de minas e galerias, do mesmo modo que sais de potássio e magnésio (silvita, carnalita e bischofita) (Fig. 8). Esses minerais são empregados em processos químicos incluindo a fabricação de materiais de construção, conservação de alimentos e agricultura.Outros depósitos, incluem vários carbonatos e sulfatos de sódio (trona, $\mathrm{NaHCO} 3, \mathrm{Na} 2 \mathrm{CO} 3.2 \mathrm{H} 2 \mathrm{O}$; thenardita, $\mathrm{Na} 2 \mathrm{SO} 4$; glauberita, CaSO4.Na2SO4; mirabilita, $\mathrm{Na} 2 \mathrm{SO} 4.10 \mathrm{H} 2 \mathrm{O}$ ), acrescido de uma série complexa de boratos (colemanita $\mathrm{Ca} 2 \mathrm{~B} 6 \mathrm{O} 11.5 \mathrm{H} 2 \mathrm{O}$; ulexita, $\mathrm{NaCaB} 5 \mathrm{O} 9.8 \mathrm{H} 2 \mathrm{O}$, e borax, (Na2B4O7.10H2O). Esses minerais são usados na agricultura, na indústria química e como material de construção.

O papel dos evaporitos, e dos processos evaporíticos, na formação de concentrações de recursos minerais é bastante diverso. Além do próprio valor econômico, a dissolução intraestratal de evaporitos pode resultar na criação de "trends" de permeabilidade que atuam de maneira importante no movimento de fluidos formadores de minérios, ou fornecer a porosidade necessária para o acúmulo de petróleo ou outro minério. Os evaporitos podem também ser de importância considerável na formação de minérios não sedimentares. Um exemplo excelente é fornecido pelo depósito de sulfetos de Níquel Cobre - Platina na Sibéria, associados a um importante depósito evaporítico. Informações geológicas e geoquímicas indicam que o magma basáltico durante sua ascensão, ao longo das falhas da bacia "rift", assimilou Enxofre dos evaporitos Devonianos: os sulfatos evaporíticos foram reduzidos para sulfetos os quais reagiram com o elemento Ferro do magma, que atuou como coletor de metais econômicos (Kyle, 1991).

\section{Evaporitos e matéria orgânica:}

No registro geológico encontram-se inúmeras associações entre carbonatos evaporativos,

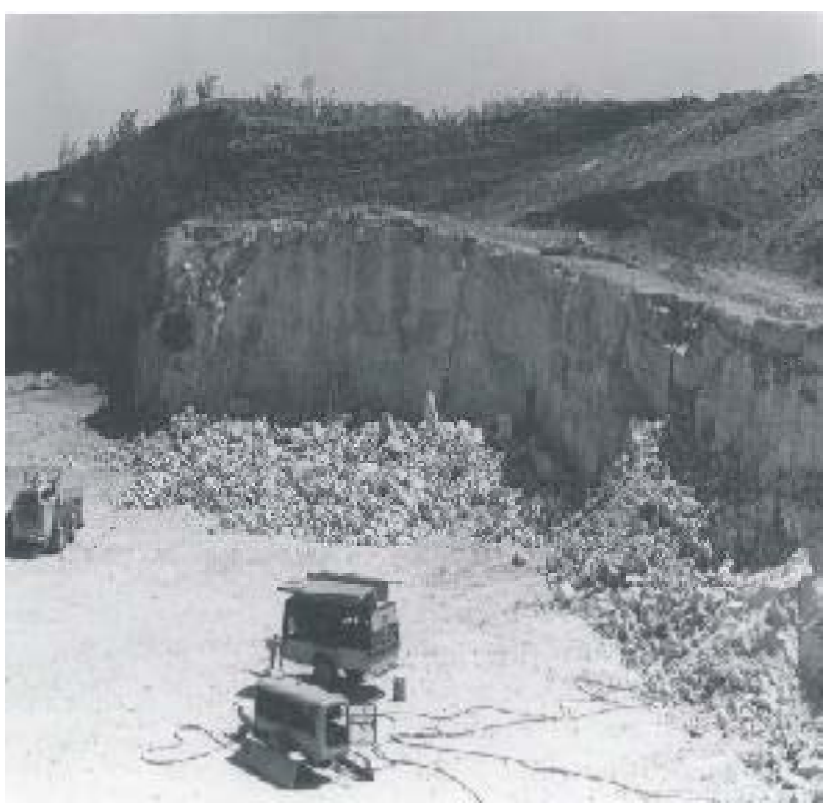

Figura 6 - Frente de exploração de gipsita e anidrita, Aptiano da Chapada do Araripe, Pernambuco.

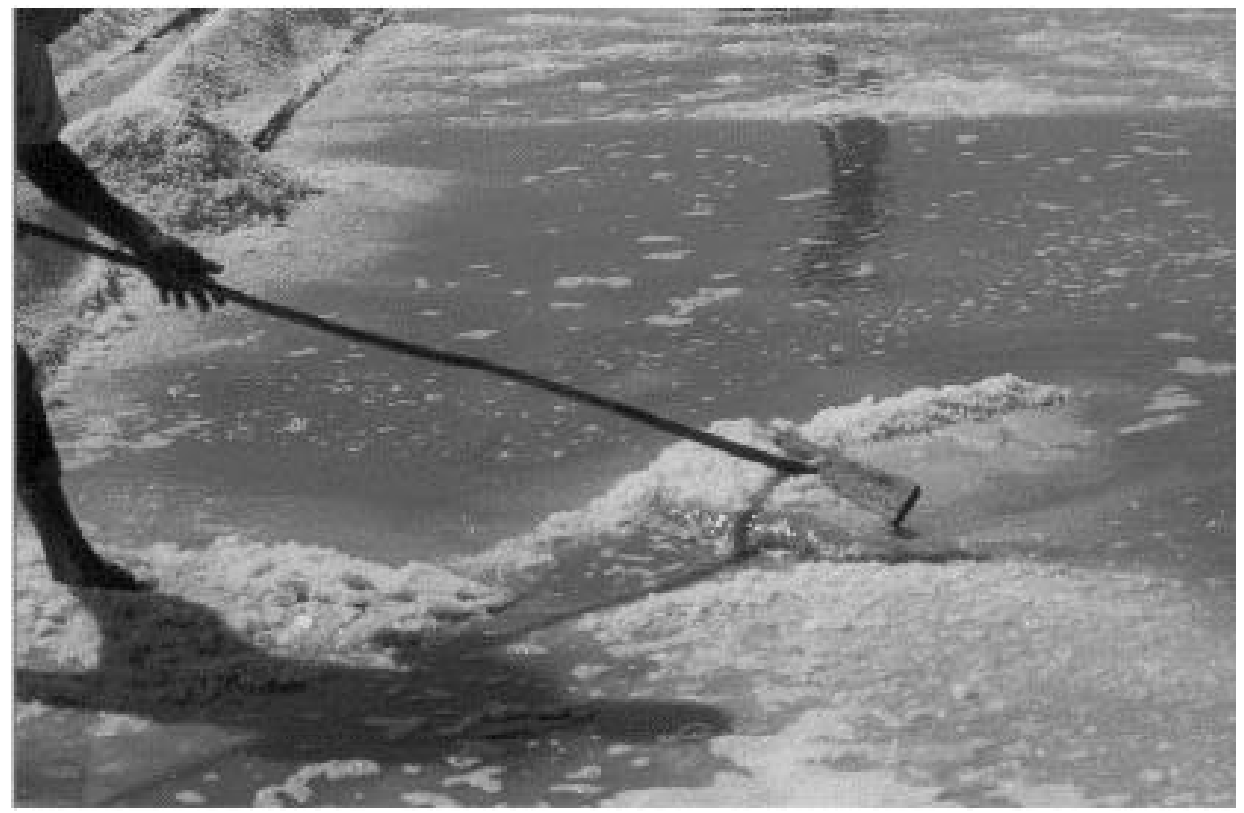

Figura 7 - Coleta artesanal de sal (halita) nas salinas da Lagoa de Araruama, Rio de Janeiro. 
evaporitos, e a ocorrência de hidrocarbonetos. Tais associações foram previamente interpretadas como conseqüência somente do fato de que os sais se comportam como barreiras à permeabilidade (Borchert e Muir, 1964). No entanto, Szatmari (1980), Kirkland e Evans (1981) e Evans e Kirkland (1988) observaram altos níveis de atividade biológica associados com a deposição de evaporitos modernos e propuseram que tais níveis de produtividade são responsáveis, pelo menos em parte, pelos hidrocarbonetos encontrados em depósitos antigos análogos desses evaporitos. Sedimentos depositados sob condições hipersalinas, particularmente aqueles depositados na fase salina de transição entre carbonatos e evaporitos marinhos, são agora reconhecidos como fontes potenciais de significantes quantidades de óleo (Benalioulhaj et al., 1994; Benali et al., 1995).

Ambientes modernos com águas de elevadas salinidades são sítios de produtividade biológica muito alta e podem ser usados como modelos para a sedimentação relacionada aos evaporitos (Rosell et al., 1998). Produtividade particularmente alta aparece na faixa de salinidade elevada (60 -150 g/L), que existe acima da faixa para a biota marinha normal (35$60 \mathrm{~g} / \mathrm{L}$ ), na qual carbonatos ricos em cianobactérias se formam e se acumulam em grandes quantidades. A matéria orgânica coletada a partir de um grande número de ambientes evaporíticos modernos tem sido examinada em termos do seu potencial para óleo bem como para a identificação de biomarcadores característicos de ambientes hipersalinos. As regiões que produzem elevados acúmulos de matéria orgânica incluem sabkhas e salinas costeiras, e lagos salinos continentais.

Nos ambientes evaporíticos modernos, os depósitos orgânicos são soterrados rapidamente, formando sedimentos argilosos ou calcários ricos em matéria orgânica interestratificados com minerais evaporíticos tais como gipsita (anidrita), glauberita, trona e halita. Essa associação e estratificação é semelhante aos depósitos encontrados em muitas seqüências evaporíticas antigas. Dependendo das condições locais, essa estratificação representa períodos de influxo de água tanto marinha como nãomarinha e que carrega argila, silte e areia. Freqüentemente elas contêm biota restrita, laminitos de bactérias e estromatolitos. Enquanto as camadas interestratificadas com os evaporitos não contêm sulfatos ou cloretos, os seus componentes, no entanto, são acumulados em ambientes muito restritos e altamente salinos (Benalioulhaj et al., 1994; Benali et al., 1995).

Schreiber et al. ( 2001) mostraram que os sedimentos orgânicos gerados em ambientes hipersalinos apresentam valores altos para a razão de

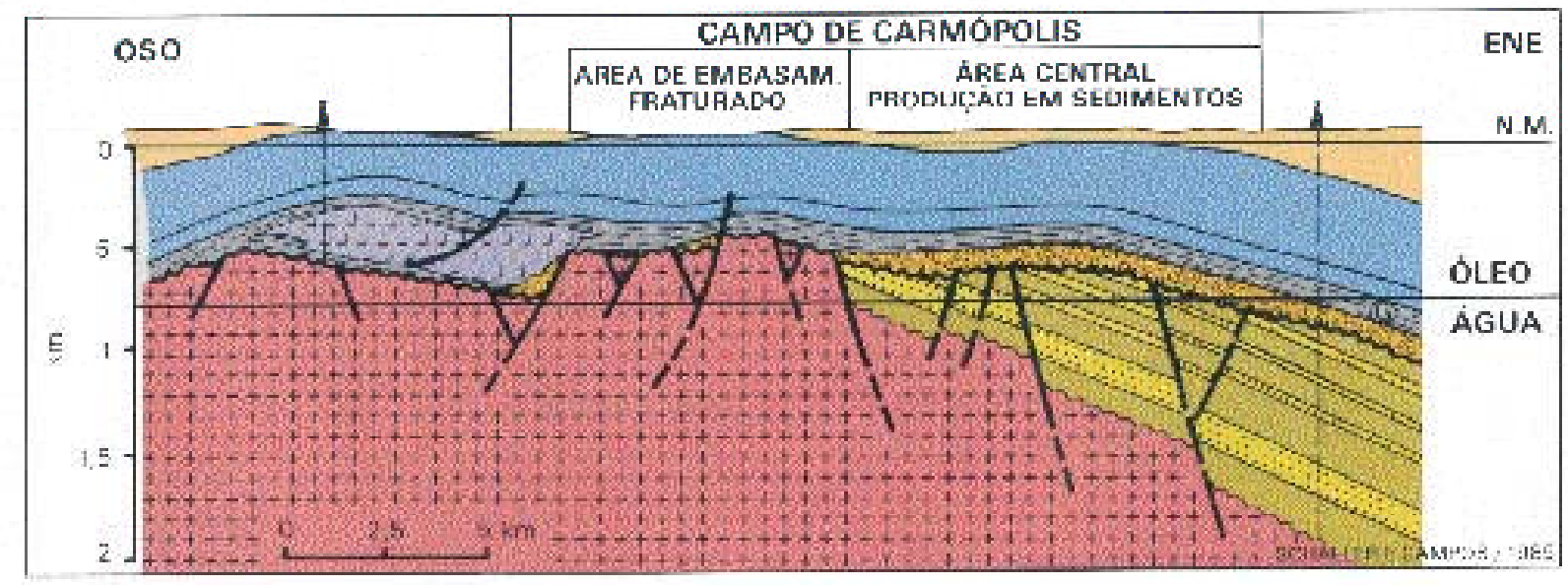

Figura 8 - Distribuição da camada evaporítica de idade Aptiana da Bacia de Sergipe (in: Viro, 1985). Na parte terrestre da bacia, a camada contendo sais de potássio é explorada. A sequência evaporítica corresponde a fase transicional marinha restrita (golfo) e representa um excelente marco estratigráfico da margem continental leste brasileira. 
$\mathrm{H} / \mathrm{C}$ demonstrando o potencial para óleo dessa matéria orgânica. Experimentos de laboratório utilizando a maturação artificial de tais sedimentos forneceram hidrocarbonetos que apresentam semelhanças com aqueles sedimentos evaporíticos geradores de petróleo em seqüências antigas. Variações no extrato total, e nas frações saturadas, aromáticas, resinas, e asfálticas evoluem para uma composição do tipo óleo.

Do mesmo modo, as distribuições dos componentes tais como n-alcanos, hopanóides e esteróides evoluem progressivamente até aqueles tipicamente encontrados nos óleos crus em ambientes evaporíticos. O que esses depósitos evaporíticos modernos demonstram é que enquanto os evaporitos realmente representam selantes excelentes para o petróleo, eles também representam sedimentos que podem ser fontes substanciais para o petróleo.

\section{Exemplo da Bacia de Sergipe:}

No Brasil, depósitos evaporíticos Aptianos ocorrem nas bacias marginais formadas através dos vários processos relativos à ruptura do Gondwana $\mathrm{e}$ formação do Oceano Attântico Sul. A fase evaporítica ocorreu quando da formação de um ambiente marinho restrito, denominado de golfo, que sucedeu a fase inicial de rifteamento, onde ambientes continentais

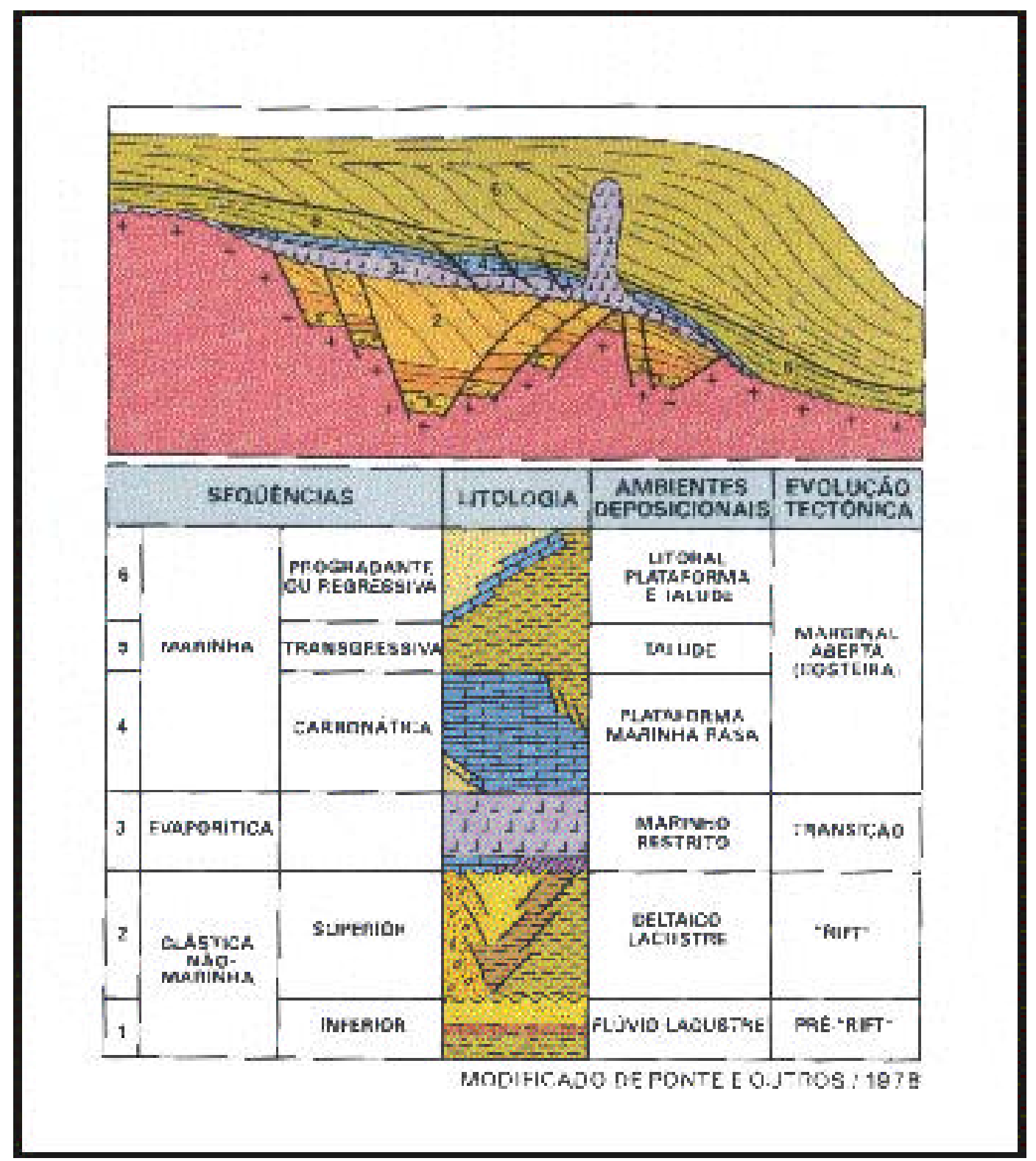

Figura 9 - Esquema ilustrativo das sequências, litologia e ambientes deposicionais presentes nas bacias marginais brasileiras (Ponte et al., 1978, in: Viro, 1985). 
prevaleciam, e antecedeu a fase marinha carbonática relativa a um mar raso que evoluiu para a bacia oceânica do Atlântico Sul (Fig. 9). Tais depósitos evaporíticos formam um pacote espesso, de $1 \mathrm{~km}$ ou mais localmente, que caracteriza um importante marco estratigráfico observado em poços e seções sísmicas obtidos na margem continental.

$\mathrm{Na}$ Bacia de Sergipe, a seqüência evaporítica ocorre em parte na porção terrestre, em subsuperfície (Fig. 8), e é formada principalmente por halita, silvinita, carnalita, além da anidrita, taquidrita e carbonatos do Membro Ibura da Formação Muribeca. Tais depósitos evaporíticos foram formados em uma série de ambientes costeiros representados por sabkhas, lagoas salinas e canais de maré (Szatmari et al., 1974; Oliver, 1995). A silvinita e carnalita (e em menor proporção também a taquidrita) vêm sendo exploradas a partir de minas e galerias subterrâneas para fins comerciais como fertilizante, principalmente. As zonas salinas são de pequenas extensões, porém têm espessuras e teores médios consideráveis, segundo Fonseca (1973). As reservas totais nas subbacias Vassouras/Taquari, Santa Rosa de Lima e Aguilhadas atingiam 2300x106 t de cloreto de potássio, 1100x106 t de magnésio, 20500x106 t de cloreto de sódio e 55x106 t de bromo (Fonseca, 1973).

\section{CONCLUSÕES}

Depósitos evaporíticos econômicos ocorrem em inúmeras bacias sedimentares de diferentes idades por todo o planeta e contêm importantes sais, tais como, gipsita, halita, trona, silvinita, carnalita, entre outros. Depósitos evaporíticos, além disso, ocorrem associados a importantes jazidas de petróleo, e é amplamente reconhecido hoje que ambientes deposicionais evaporíticos podem conter grande quantidade de rocha fonte. Os ambientes modernos também fornecem evaporitos, como ocorre nas salinas naturais ou artificiais onde se faz a extração da halita, o sal de cozinha, recurso mineral da maior importância desde tempos imemoriais. No Brasil, o Membro Ibura da Formação Muribeca, correspondente ao Aptiano da Bacia de Sergipe, contém camadas em subsuperfície de sais de potássio (silvinita e carnalita) exploradas comercialmente.

\section{AGRADECIMENTOS}

Ao revisor Flávio J. Feijó pelas revisões e sugestões. Aos editores desta edição especial sobre Recursos Minerais Marinhos pelo convite.

\section{REFERÊNCIAS}

BENALI, S., SCHREIBER, B.C., HELMAN, M.L. \& PHILP, R. P.- 1995 - Characterization of organic matter from a restricted/evaporative sedimentary basin: Upper Miocene of Lorca (SE Spain). Am. Assoc. Pet. Geol. Bull., 79, 816830.

BENALIOULHAJ, S., SCHREIBER, B.C. \& PHILP, R.P.- 1994 - Relationship of organic geochemistry to sedimentation under highly variable environments, Lorca Basin (Spain): Preliminary results. In: Renaut, R.and Last, Wm. (Eds.), Sedimentology and Geochemical Record of Modern and Ancient Saline Lakes. Soc. Econ. Paleontol. Mineral., Special Publication, 50, 315324.

BORCHERT, H. \& MUIR, R.O. - 1964 - Salt Deposits. D. Van Nostrand Company, Ltd., London. 388pp.

CURTIS, R., Evans, G., Kinsman, D.J.J. \& Shearman, D.J. - 1963 - Association of dolomite and anhydrite in the recent sediments of the Persian Gulf. Nature, 197, 6779-6800.

EVANS, R. \& KIRKLAND, D.W. - 1988 -. Evaporitic environments as a source for petroleum. In: Schreiber, B C. (Ed.), Evaporites and Hydrocarbons. Columbia University Press, New York, 256-299.

FONSECA, J.C. - 1973 - Evaporitos de Sergipe. Anais do XXVII Congresso Brasileiro de Geologia, ps. 185-196. Aracajú/Se.

KENDALL, A.C. - 1984 -Evaporites. Em: Walker, R.G. (ed.), Facies Models. Second Edition. Geoscience Canada Reprint Series 1, Cap. 17, p. 259-296.

KIRKLAND, D.W. \& EVANS, R. - 1981 Source-rock potential of evaporitic environment. Am. Assoc. Petrol. Geol. Bull., 65, 181-190.

KYLE, J.R. - 1991 - Evaporites, Evaporitic Processes And Mineral Resources. In: Melvin, J.L. (ed.), Evaporites, Petroleum and Mineral 
Resources. Developments in Sedimentology 50, Cap. 6, p. 477-533.

OLIVER, F.Z. - 1997 - Seqüência Evaporítica Ibura da Bacia de Sergipe, Revisão de Fácies Sedimentares, Paleoambientes Deposicionais e Potencialidades na Geração de Petróleo. Dissertação de Mestrado, Departamento de Geologia da UFF, 145ps.

ROSELL, L., ORTİ, F., KASPRZYK, A., PLAYA, E. \& PERYT, T.M. - 1998- Strontium geochemistry of primary Miocene gypsum: Messinian of southeastern Spain and Sicily and the Badenian of Poland. Journal Sedimentary Research, 68, 63-79.

SCHREIBER, B.C. - 1986 - Arid shorelines and evaporites. In H.G. Reading, ed., Sedimentary environments and facies (2nd ed.), Blackwell Scientific Publishers, pp.189-228, Oxford.

SCHREIBER, B.C. \& TABAKH, M.EI-2000 Deposition and early alteration of evaporites. Sedimentology. Millennium Reviews. 47 (Suppl.), 215-238.

SCHREIBER, B. C., PHILP, R. P., BENALI, S., HELMAN, M. L., LANDAIS, P.,C.G.ST.C.,
DE LA PEÑA, J. A, MARFIL, R., COHEN, A. D. \& KENDALL, C.ST.C.- 2001 Characterization of organic matter formed in hypersaline environments: hydrocarbon potential and biomarkers through artificial maturation studies. Jour. Petroleum Geology, 24, 309-338.

SZATMARI, P. - 1980 - The Origin Of Oil Deposits: A Model Based On Evaporites. Anais Do XXXI Congresso Brasileiro De Geologia, Camboriú/SC, Vol. 1, 455-499.

SZATMARI，P. , CARVALHO, R.S. de ,SIMÕES, I.A. TIBANA, P. \& LEITE, D.C. - 1974 - Evaporitos de Sergipe, v. 1, Projeto Evaporitos, SEM - Ba / SEPES, Aracajú, 159 p.

VIRO , E.J. (Coord.) - 1985 - Avaliação De Formações No Brasil. Schlumberger.

WARREN, J.K. -1989.- Evaporite Sedimentology. Importance in Hydrocarbon Accumulation. Prentice Hall, 285ps.

WARREN, J.K. - 1999 - Evaporites, their evolution and economics. Blackwal Science.

\section{NOTE ABOUT THE AUTHORS}

Maria Augusta Martins da Silva

Geóloga formada pela UFRJ e mestre em geologia costeira pela UFRGS. Pela Columbia University (N.Y./ U.S.A.) obteve mestrado e doutorado desenvolvendo pesquisa sobre análise de bacias, em especial a fase evaporítica das bacias de Araripe e Sergipe. O estudo dos evaporitos modernos em salinas vem sendo conduzido como análogo moderno dos depósitos antigos. Esta é uma das linhas de pesquisa da professora na UFF onde é responsável pelos cursos de Sedimentologia e Ambientes Deposicionais.

\section{B. Charlotte Schreiber}

Começou seus estudos sobre evaporitos em 1970 após inúmeros anos de trabalho sobre sedimentação marinha, principalmente no Lamont-Doherty
Geological Observatory da Columbia University (N.Y./U.S.A.). Dra. Schreiber tem trabalhado com evaporitos de idades variando do Pré-cambriano ao Recente e vem viajando exclusivamente a fim de observar evaporitos em seus ambientes naturais. Por muitos anos vem sendo editora associada e revisora da AAPG Bulletin, J.S.P., J.S.R., Sedimentology e Sedimentary Geology. Ela é autora/co-autora de 63 artigos, editora de 4 livros e responsável por dezenas de cursos.

\section{Carla Luiza dos Santos}

Geógrafa pela UFF, com mestrado em geologia e geofísica marinha pelo Departamento de Geologia da UFF, quando desenvolveu pesquisa sobre dinâmica costeira. Uma das pesquisas realizadas pela pesquisadora é a relativa aos mecanismos de formação de sais nas salinas. 